\title{
Field test of an automatic controller for solid-set sprinkler irrigation
}

\author{
Zapata, . $^{1}{ }^{*}$, Salvador, . $^{1}$, Cavero, J. $^{1}$, Lecina, S. $^{2}$, \\ López, C. ${ }^{1}$, Mantero, ${ }^{3}{ }^{3}$, Anadón, $R .^{1}$ and Playán, E. ${ }^{1}$
}

\section{$\underline{\text { ABSTRACT }}$}

The application of new technologies to the control and automation of irrigation processes is becoming very important, and the automatic generation and execution of irrigation schedules is receiving growing attention. In this paper, a prototype automatic irrigation controller for solid-set systems is presented. The device is composed by software and hardware developments. The software was named Ador-Control, and it integrates five modules: the first four modules simulate drop trajectories, water distribution, crop growth and yield, and the last module ensures bidirectional communication between software and hardware. Decision variables based on soil, crop and irrigation performance indexes were used to make real-time irrigation decisions. A randomized experimental design was designed to validate the automatic controller over a corn crop during two seasons. Three treatments were analyzed: T0) manual programmer or advanced farmer; T1) automatic scheduling controlled by indexes based on soil simulated water content and irrigation performance; and T2) advanced automatic scheduling controlled by simulated thresholds of crop and irrigation indexes.

\footnotetext{
${ }^{1}$ Dept. Soil and Water. EEAD-CSIC. Avda Montañana, 1005. 50059 Zaragoza. Spain. v.zapata@csic.es, rsalvador@eead.csic.es, jcavero@eead.csic.es, mclomar@gmail.com, anadonraquel@hotmail.com, enrique.playan@csic.es

${ }^{2}$ Dept. Soil and Irrigation (EEAD-CSIC Associated Unit). Agrifood Research and Technology Centre of Aragon (CITA), Aragon Government. Avda Montañana, 930. 50059 Zaragoza. Spain. sergio.lecina@cita-aragon.es.

${ }^{3}$ C2 Comunicación, San Miguel 2, 9A. 50001 Zaragoza, Spain. nacho@c2comunicacion.com

* Corresponding author
} 
Experimental results in 2009 and 2010 indicated that automatic irrigation treatments resulted in similar maize yield but using less water than manual irrigation (10\% between $\mathrm{T} 0$ and $\mathrm{T} 1$, and $18 \%$ between $\mathrm{T} 0$ and $\mathrm{T} 2$ ). 


\section{$\underline{\text { INTRODUCTION }}$}

The application of new technologies to the control and automation of irrigation is becoming a very relevant issue in the last decade. Although automation of irrigation execution (through irrigation controllers) is now widespread, the automatic scheduling of irrigation is receiving growing attention. This is due to a number of factors: 1) generalization of real-time, digital information on crop water requirements; 2) increased access to this information from remote sites through wireless connections; 3) communication possibilities offered by the telemetry / remote control systems currently being installed in collective pressurized networks and in individual farms; and 4) the cost effectiveness of these technologies in developed countries when compared to labor costs.

The spatial variability of water application in sprinkler irrigation systems is due to technical design problems (spatial variability of pressure and discharge, sprinkler spacing) and to meteorological constrains (mainly wind speed and evaporative demand). Technical design problems have been addressed through engineering approaches, such as head loss analysis, sprinkler overlapping, flow control nozzles or pressure regulators. This approach has improved uniformity in sprinkler irrigated farms, but has not been succeeded in to controling the effects of adverse meteorology. Low irrigation uniformity results in large variability in water application. As a consequence: crop yield and yield quality can be reduced (Stern and Bresler, 1983; Bruckler et al., 2000; Dechmi et al., 2003), pumping costs escalate as a result of low irrigation efficiency; and environmental problems multiply.

Scheduling irrigation events considering the abovementioned variability and aiming at optimizing water productivity is a major challenge. Solving this problem may involve 
using automated, real-time technologies. In the following paragraphs, a non-exhaustive list of four types of solutions applied to different irrigation contexts is discussed.

The first solution has been developed for sprinkler irrigation machines (centre pivots and rangers). Precision irrigation water application is based on controlling the variability in irrigation pressure, soil properties and topography. This approach is often based on the use of standard, off-the-shelf components and control algorithms applied at the emitter level (Roth and Gardner, 1989; Evans et al., 1995; Camp and Sadler, 1998; Evans et al., 2000; King and Kincaid, 2004).

The second type of solutions has been specifically designed for urban landscapes using drip irrigation systems, with the goal of increasing irrigation efficiency. Control devices and algorithms have been developed based on weather information and / or soil moisture sensors (Haley et al., 2007; Cardenas-Lailhacar and Dukes, 2010; McCready and Dukes, 2011). These devices can address the spatial variability of soil water availability by exploiting a network of soil moisture sensors.

The third type of solutions has been developed for drip irrigated fruit orchards. Solutions have addressed the development of automatic irrigation controllers based on continuous monitoring of plant or soil water status (Jones, 1990; Goldhamer et al., 1999; Intringliolo and Castel, 2005). Naor et al. (2006) reported that the number of measurements required for the correct representation of orchard water status is affected by the sensitivity of the selected water stress indicator and by the variability of the measurements. Scientific effort is still needed to develop practical, hands-on procedures improving current water application in irrigated orchards (Zapata et al., 201X). On the other hand, simple, reliable and low-cost sensors and controllers need to be developed in order for farmers to adopt these approaches for practical irrigation scheduling (Nadler and Tyree, 2008). 
The fourth type of solutions is based on simulation tools. Coupled solid-set irrigation system and crop models (Dechmi et al., 2004a and 2004b; Playán et al., 2006; Zapata et al., 2009) have been developed to support irrigation decision making. Target variables may involve irrigation performance indexes (optimizing irrigation), crop indexes (yield) or a combination of both (water productivity). This type of solutions addresses the management problems of solid-set irrigated plots, which can be summarized in maximizing irrigation uniformity and efficiency, minimizing sprinkler evaporation losses and energy costs, and maximizing crop productivity.

In this paper an automatic irrigation controller prototype for solid-set sprinkler irrigation based on the fourth solution above is presented. The automatic irrigation controller prototype includes software and hardware developments. The software evolved from previous works (Dechmi et al., 2004a and 2004b; Playán et al, 2006 and Zapata et al., 2009), while the hardware was a research, non-commercial prototype capable of monitoring the irrigation environment and executing irrigation orders. The main objective of the prototype was to minimize farmer intervention on irrigation activities (reducing human subjectivity, increasing labor productivity), while maintaining an adequate level of irrigation performance and without affecting crop yield (optimizing water productivity). A field experiment was designed to test and validate the prototype in a corn crop during two irrigation seasons. 


\section{MATERIAL AND METHODS}

\section{Software description}

The Ador-Network model presented by Zapata et al. (2009) was modified to control the present irrigation controller prototype. The original model was composed of four modules interchanging input and output data in order to schedule irrigation in a given area. The four software modules are: Ador-Sprinkler, Ador-Crop, Ador-Network and Ador-Decision. The joint operation of the first two modules was presented by Dechmi et al. (2004a and 2004b), simulating the interaction between a solid-set irrigation system and a corn crop. The joint operation and interaction of the four modules was presented by Zapata et al. (2009) to simulate at machine speed the centralized, automatic control of an irrigation district. In this research the simulation of irrigation scheduling and operation was executed in real time. A new module, Ador-Communication, was integrated in the software to permit bidirectional communication between the software and the hardware components of the prototype, as well as with communication networks. The new software, integrating the five abovementioned components, was named Ador-Control. In the following paragraphs, the main aspects of the implementation of each module are presented:

Ador-Network. This module implements the description of the irrigated area from a hierarchical point of view, referring to the irrigation network conveyance capacity (not addressing hydraulics). This module also contains the division of the irrigated area into farms, irrigation plots and irrigation blocks, following the definitions provided by Zapata et al. (2009). While a farm is characterized by land tenure (one owner), an irrigation plot is characterized by land use (different irrigation systems or crops result in different plots within a farm). The areas in which an irrigation plot is divided for sequential sprinkler irrigation are the irrigation blocks. 
Ador-Sprinkler. The module is based on sprinkler droplet ballistics, and was used as described in Zapata et al. (2009). Irrigation performance is affected by two processes driven by meteorological conditions: sprinkler evaporation losses and wind-induced distortion of the water application pattern. High wind speed (WS, $\mathrm{m} \mathrm{s}^{-1}$ ) and low relative humidity $(R H, \%)$ result in high sprinkler evaporation losses and low uniformity. The output of this module is the simulated water application in 25 points uniformly distributed within one sprinkler spacing. Consequently, each irrigation block was characterized by a set of 25 simulation points.

Ador-Crop. This module simulates the soil water balance, crop water status and yield reduction following the principles and procedures set in CropWat (Smith, 1992). The crop coefficients and the length of the four FAO corn phenological stages were determined following Martinez-Cob (2008). This author presented a crop coefficient equation using the fraction of thermal units as independent variable. The duration of the corn phenological stages was obtained from Cavero et al. (2009). Ador-Crop was run in each of the abovementioned 25 irrigation points in order to characterize the effect of irrigation on evapotranspiration and crop yield in each irrigated block.

Ador-Decision. This module is the core of Ador-Control, since decision making is critical for the real-time generation and update of irrigation schedules. Irrigation decisions can be based on estimated irrigation performance, soil water availability, crop status indexes or a mixture of them. These variables are related to the variability of water application inside each irrigated block. Three decision variables will be used to govern irrigation decisions in this research:

1) $P A E_{l q}(\%)$, is the Potential Application Efficiency of the Low Quarter (Merriam and Keller, 1978; Burt et al., 1997). It can be expressed as: 
$P A E_{l q}=\frac{\text { average depth of irrigation water contributing to target }}{\text { average depth of irrigation water applied such that } \mathrm{d}_{\mathrm{lq}}=\text { target }} 100$

where $d_{l q}$ is the low quarter irrigation depth. In this equation, sprinkler evaporation losses were considered as net water losses.

$P A E_{l q}$ greatly depends on meteorological conditions, particularly on wind speed and relative humidity (Zapata et al., 2009). A minimum value of $P A E_{l q}\left(P A E_{l q M I N}\right)$ is required for automatic irrigation. As a consequence the controller will have to identify periods of time with adequate meteorological conditions. In practice, depending on $P A E_{l q M I N}$, the on farm irrigation system and the local climatology, the automatic controller will accumulate irrigation events during the nighttime and during low-wind daytime periods.

2) Equivalent Stress (ES, days) applies to an irrigation plot divided in $n$ blocks and cultivated to a given crop. ES can be expressed as:

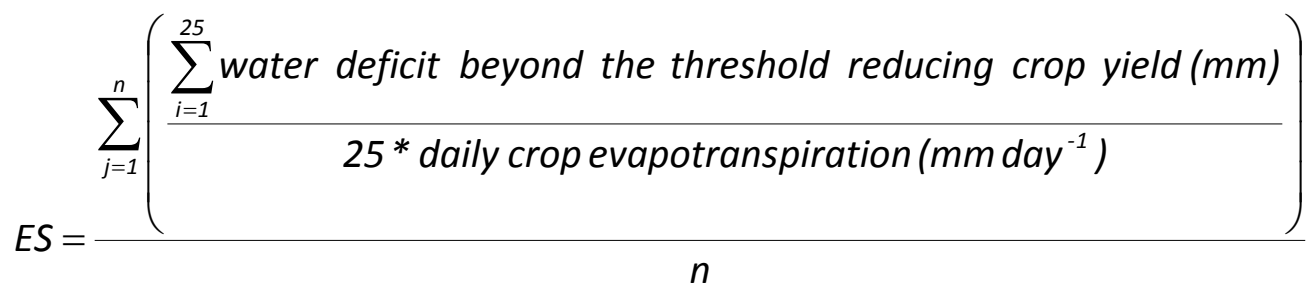

$E S$ can be interpreted as the number of days that the irrigation plot has been under water stress (Zapata et al., 2009). ES can be daily determined from Ador-Crop variables considering the water deficit threshold reducing crop yield, as defined by Allen et al. (1998).

3) Soil Water Depletion (SWD). Crop yield is reduced when soil water depletion exceeds $S W D_{M A X}$. A simplified soil water balance can be daily updated in an irrigation plot to estimate $S W D$ : 


$$
S W D_{\text {today }}=S W D_{\text {yesterday }}+K c_{\text {yesterday }} * E T_{0 \text { yesterday }}-P_{\text {yesterday }}-I D_{N \text { yesterday }}
$$

where $K c$ is the crop coefficient, $E T_{0}$ is reference evapotranspiration, $P$ is precipitation and $I D_{N}$ is net irrigation depth. This simplified soil water balance does not require Ador-Crop information, and can be run with minimum computing capacity.

This set of decision variables controlling an automatic irrigation strategy should be calibrated and validated to the local conditions of the network/farm: irrigation system design, meteorology, soil and crop.

Ador-Communication. This module communicates the software and hardware components of the prototype. It elaborates simple irrigation commands which are translated into messages sent to the hardware (electric signals to solenoids, resulting in valve opening or closing). The pulses or voltages received by the hardware from local sensors (flow meter, pressure transducer, wind speed, wind direction and relative humidity) are translated by this module into irrigation system status and environmental values which constitute input for irrigation decisions. Communication between software and hardware was in practice performed through a radio modem. This module also established connections with the internet (agrometeorological data, status reporting) and a mobile phone network (for alarm broadcasting).

Figure 1 shows a schematic flow chart of the input data, the intermediate output data elaborated by the different modules and the final irrigation schedule elaborated and implemented by Ador-Control. Input data are classified in different types. The farm configuration data must be manually input to the software and includes irrigation system design data, soil characteristics and crop features. The irrigation system data should be incorporated once, but the soil and crop data should be seasonally refreshed. 
Meteorological data was input in the model from two sources of data: average daily data, and hourly data. These data were used for crop modeling and short-time decision making, respectively. Daily data were automatically obtained through an on-line connection to the nearest agrometeorological station of the SIAR network (www.magrama.gob.es/siar/informacion.asp). In order to avoid problems from discontinuities in access to this database, a historical daily meteorological database was built in the software. When the access to SIAR failed, crop modelling was performed with average meteorological data. Corrections were performed once real data were again available. Hourly data were obtained from irrigation and meteorological sensors installed at the hardware prototype. Irrigation sensors served the purpose of supervising operation, while meteorological sensors characterized the farm site. Irrigation performance was evaluated using the Coefficient of Uniformity (CU, \%) (Merriam and Keller, 1978), as well as the Application Efficiency ( $A E$, \%) and Irrigation Efficiency (IE, \%) indexes (Burt et al., 1997). As a result of the operation described in Figure 1, automatic, real-time, crop-wise, environment-wise and economically oriented sprinkler irrigation schedules were elaborated and continuously updated.

\section{Hardware description}

The hardware prototype was composed by sensors, a low level automaton (SATEL, ILINK100 I/O-converter, SATEL Oy, Finland) and the radio communication infrastructure (antennas and radio modems). Two types of sensors, meteorological and hydraulic, with different functionalities, integrated the hardware. Meteorological sensors included a wind speed and direction sensor (model 7911, Davis Instruments, Hayward, CA, USA) and an air relative humidity sensor (model HMP45, Vaisala, Campbell Scientific, Logan, Utah, USA). Both sensors were installed at $2.0 \mathrm{~m}$ and 3.5 m above soil level, respectively, and connected to the automaton. Hydraulic sensors 
included a flow meter (model Woltman WP DN 100 mm, 4", Zenner, Germany) and a pressure sensor (model Gems 2200B, Gems Sensors Inc., Basingstoke, Hampshire, England) located at the water supply point and connected to the automaton. Sensor reading was performed every hour. This frequency derived from the decision to update the irrigation schedule every hour. Meteorological data were used to forecast irrigation performance. Hydraulic data were used to supervise the irrigation controller operation and the irrigation network status. Alarm protocols based on maximum and minimum threshold pressure, discharge and input voltage were established.

\section{Field experiment}

A field experiment was designed to validate the automatic controller prototype operation and to evaluate its performance in comparison with conventional irrigation scheduling and programming. The experiment was conducted in a 2.0 ha solid-set facility located at the experimental farm of the Aula Dei Agricultural Research Centre in Montañana (Zaragoza, NE Spain). Geographical coordinates are $41^{\circ} 43^{\prime} \mathrm{N}$ latitude and $0^{\circ} 49^{\prime} \mathrm{W}$ longitude, and elevation is $225 \mathrm{~m}$ above mean sea level.

Owing to experimental limitations, access to water was shared with another experimental field external to this research. Following a common practical arrangement, two days of the week (Tuesday and Thursday) were excluded from the available time for irrigation of this experiment and reserved for irrigating the external field.

The field was equipped with at solid-set system composed of RC-130 sprinklers (Riegos Costa, Lérida, Spain), implementing 4.4 and $2.4 \mathrm{~mm}$ nozzles, located at an elevation of $2.3 \mathrm{~m}$ over the soil surface, using a rectangular $18 \times 18 \mathrm{~m}$ arrangement, and operating at a nozzle pressure of $300 \mathrm{kPa}$. The experimental field counted on 64 sprinklers and 12 
experimental plots composed by one sprinkler spacing each (Figure 2). The area of each experimental plot was $18 \times 18 \mathrm{~m}^{2}$.

Three experimental treatments were established:

- $\quad$ T0, representing manual irrigation scheduling and programming, as performed by an advanced farmer. Such a farmer would use the evapotranspiration information provided by a conventional irrigation advisory service to produce a weekly irrigation schedule. Once scheduled, the irrigation event will proceed without modifications for one week.

- $\mathrm{T} 1$, representing a simplified automatic controller which can run autonomously in the field. T1 does not make use of Ador-Crop for irrigation decision making. This treatment uses a minimum irrigation performance $\left(P A E_{\text {lqMIN }}\right)$ and a maximum soil water allowable depletion $\left(S W D_{M A X}\right)$ as control variables. Minutes before midnight, a simplified water balance is run for each irrigation block. SWD for the previous day is updated with crop evapotranspiration, precipitation and net irrigation depth. Net irrigation depth is determined for each irrigation event from the gross irrigation depth and an estimation of irrigation efficiency. Irrigation efficiency was estimated as $P A E_{l q}$ (using Ador-Sprinkler) plus the value of $\Delta_{I E-A E}(\%)$, a factor accounting for the difference between irrigation efficiency and the seasonal average of application efficiency. When $S W D$ exceeds $S W D_{M A X}$, irrigation is scheduled for the next day. Meteorological conditions are checked every hour while the irrigation event lasts. If meteorology becomes unsuitable (foreseen $P A E_{l q}<P A E_{l q M I N}$ ) irrigation stops for an hour. After an hour, meteorological conditions are reassessed and irrigation can be resumed. Thresholds for $S W D_{M A X}$ and $P A E_{M I N}$ must be calibrated for the experimental conditions before running the experiment. 
- T2, representing an automatic controller based on the use of Ador-Crop. The intense computational requirements would in practice require either an on-farm PC or a remote PC communicating with the farm every hour. The simulated irrigation depth (Ador-Sprinkler) received at each point within a sprinkler spacing is used as an input to Ador-Crop (Dechmi et al., 2004a and 2004b). This permits to characterize water stress, and to estimate the average time since stress started in this treatment (ES). Decisions are based on ES and on irrigation performance $\left(P A E_{\text {lqMIN }}\right)$. The two decision variables are hierarchically used in this treatment. $P A E_{l q}$ can suspend irrigation at any hourly interval. However, once the threshold value of $E S$ ( $\left.E S_{\text {MAX }}\right)$ is reached, irrigation is executed independently of the meteorological conditions. This rule allows applying inefficient irrigations to avoid large affections to crop yield. Threshold values of $E S$ and $P A E$ require calibration for the experimental conditions.

In this experiment, the irrigation network was composed by three hydrants, each of them irrigating a treatment. Six irrigation blocks (labeled from 0 to 5) were defined in each treatment. The number of blocks, combined with the gross application rate (5.29 $\mathrm{mm} \mathrm{h}^{-1}$ ), the average peak crop water requirements $\left(10.7 \mathrm{~mm} \mathrm{~d}^{-1}\right)$ and the irrigation time availability (5 days out of 7 ), resulted in a peak network occupation of $70 \%$. This represents the minimum time slack to select periods of adequate meteorology for sprinkler irrigation during the peak of the season. The network occupation (70\%) for the experimental field was common in the area and resulted adequate for windy areas (Zapata et al 2007).

The sequential irrigation of the six irrigation blocks of each treatment was arranged by the software. Only irrigated block 0 (IB0) of each treatment was physically represented in the experimental field. The other five irrigation blocks of each treatment were virtual: 
their irrigation time was simulated and allocated by the automatic programmer, but they did not exist. A randomized experimental design containing four replicates (experimental plots) of IB0 per treatment was performed. A total of twelve experimental plots (three treatments, four replicates) composed the field experiment (Figure 2). Corn (Zea mays L.) cv. Pioneer PR34N43 was sown on 20 April in 2009 and on 21 April in 2010, at a density of 85,000 plants $\mathrm{ha}^{-1}$ and at $0.75 \mathrm{~m}$ distance between rows. Agronomical practices (fertilization and application of herbicides and insecticides) were the same in all experimental plots.

Figure 2 presents an aerial picture of the field experiment, including the location of the experimental hardware and software. The software PC was located in an office of the principal building of the Research Centre, around $500 \mathrm{~m}$ far away from the field experiment. The experimental design of the three irrigation treatments (the IB0 of each treatment) and its four replicates are also presented in Figure 2. A detailed sketch of the elemental experimental plot with the location of the measurement points of all soil and crop monitored variables is also presented.

Once the decision to irrigate a given treatment is made, all its irrigation blocks are sequentially irrigated. The irrigation sequence can be established by the user based on a user-planned or a random starting irrigation block. In all software executions reported in this paper, the first sector to be irrigated in each irrigation event was randomly determined. The user can also determine the irrigation time per block. An irrigation time of $4 \mathrm{~h}$ was used in all simulations and experiments, as a common practice in the area. Given the characteristics of the experimental field, this irrigation time was equivalent to a gross irrigation depth of $21.2 \mathrm{~mm}$.

Soil samples were taken before sowing at each experimental plot in 2009 to determine field capacity (FC, \%), wilting point (WP, \%), soil water holding capacity (WHC, \%) 
and initial gravimetric soil water content $\left(S W C_{I}\right) . S W C_{I}$ was also determined in 2010 before sowing (Figure 2). Soil samples were also taken after harvesting in both crop seasons to determine the final gravimetric soil water content $\left(S W C_{F}\right)$. Differences in the measured soil variables between treatments were established using analysis of variance.

During the crop season of 2009, plant height and percent intercepted photosynthetically active radiation (IPAR) were measured twice at the experimental plots. Crop height was measured at crop stage of ten leafs (V10) and at maximum height, using a ruler (Figure 2). Ten plants were measured at each experimental plot at three rows. The plants were marked for subsequent measurements. IPAR was measured at solar noon on 23 July and 26 August, using a 1-m long ceptometer (Sunscan Canopy Analysis System, Delta-T, Cambridge, UK) and a sunshine sensor (BF3, Delta-T, Cambridge, UK). Five points were marked at three corn rows to measure the photosynthetically active radiation below the corn plants, at the same time measurements were taken above the corn plant with the sunshine sensor (Figure 2).

At harvest (20 October 2009, 18 Oct. 2010), the corn plants located in a 3-m-long section of two different rows $\left(4.5 \mathrm{~m}^{2}\right)$ in each experimental plot were hand harvested by cutting them at the soil surface. The grain was separated from the cob and stalks, and both parts were dried at $65^{\circ} \mathrm{C}$. Total biomass and harvest index $(H I)$ were determined. The experimental plots $(18 \times 18 \mathrm{~m})$ were machine harvested with a combine, and the grain was weighed with a 1-kg-precision scale. A subsample of grain was collected to measure the grain moisture. Grain yield was adjusted to standard $140 \mathrm{~g} \mathrm{~kg}^{-1}$ moisture content. 


\section{Software and hardware interaction example}

Figure 3 presents a graphical example of the irrigation controller operation during Julian days 206 and 207, of the 2010 experiment. For each irrigation block (IB0 to IB5) per treatment (T0, T1 and T2) the hourly sequence of activities is shown. As reported before, the irrigation time per block and event was 4 hours. The first IB of the sequence to be irrigated for each treatment was randomly selected. The irrigation of T0 (manually scheduled) started at the beginning of Julian day 206 by IB4. The irrigation sequence followed its normal order until the irrigation round was completed at the end of Julian day 206. T1 did not irrigate during day 206. At the end of day 206, SWD was updated for T1. Since the value exceeded the maximum, a new irrigation event was planned for day 207. Irrigation could not start at midnight, since the meteorological conditions resulted in estimated $P A E_{l q}$ below the minimum (due to a short windy period). Conditions improved one hour later, and irrigation started by IB3 at 1 GMT. During day 207, irrigation stopped and resumed twice. On day 206, treatment T2 was irrigating IB0, completing an irrigation event initiated on the previous day. At 9 GMT the irrigation of T2 was interrupted at IB2 because threshold values for the irrigation performance indexes $\left(P E A_{\text {lqMIN }}=50 \%\right)$ were not fulfilled. Irrigation resumed one hour later. At 11 GMT the irrigation of T2 stopped again at IB3. In this case, irrigation only resumed at 23 GMT, once PEA $A_{l q}$ reached the threshold. At the end of 206, Ador-Crop was run the T2 field. The value of ES exceeded the maximum (0.5 days), and irrigation proceeded all day despite the fact that conditions were inadequate for irrigation during part of the day.

Differences in irrigation scheduling between treatments T0 and T2 are shown in Figure 3. During day 206, T0 was insensible to meteorological conditions, while T2 avoided adverse conditions for sprinkler irrigation (the right part of Fig. 3 presents hourly values 
of selected meteors and irrigation performance indexes). Differences between $\mathrm{T} 1$ and T2 are shown during Julian Day 207: T1 stopped irrigation owing to the PAElq threshold, while T2 did not stop because water stress was threatening crop yield (ES values were 0.4 and 0.6 days for simulated days 206 and 207, respectively).

\section{Calibration of variables controlling the automatic treatments T1 and T2}

The automatic controller software implements a parameter calibration mode, running at machine speed. This mode used hourly and daily meteorological data from a database, scheduled irrigation events on T0, T1 and T2 as explained above, and determined the effects of a given parameter set on crop yield and water application using the Ador-Crop model to reproduce the field conditions for all treatments. In the case of T2, Ador-Crop was also used to schedule irrigation. In the calibration mode all interaction with the automaton was replaced by access to meteorological databases or instructions to AdorCrop.

As previously discussed, the decision variables for $\mathrm{T} 1$ included $P A E_{\text {lqMIN }}$ and $S W D_{M A X}$. Calibration was performed for the experimental irrigation system design using a local meteorological data series including the period from 1995 to 2008. This was the only data period available with the required detail. Five values of $P A E_{l q M I N}(0,40,45,50$ and $55 \%)$ were combined with three values of $\operatorname{SWD}_{M A X}(10,20$, and $25 \mathrm{~mm})$. The pair of values of these variables optimizing average irrigation depth, average irrigation performance and average grain yield (i.e., water productivity) was selected. The calibration phase was also used to estimate the value of $\Delta_{I E-A E}$ from simulated results of $I E$ and seasonal average $A E$.

Decision variables for $\mathrm{T} 2$ included $P A E_{\text {lqMIN }}$ and $E S_{\text {MAX. }}$. Calibration was performed for the experimental irrigation system design and for the same meteorological data series. 
Three values of $E S_{\text {MAX }}(0.25,0.50$ and 0.75 days) were combined with five values of $P A E_{\text {lqMIN }}(0,40,45,50$ and 55\%). The criterion for selecting optimum values of the decision variables was the same as for $\mathrm{T} 1$. 


\section{RESULTS AND DISCUSSION}

Experimental validation was performed in 2009 and 2010 using meteorological data from the SIAR agrometeorological network. The largest variability between seasons was observed for precipitation, while the lowest variability was observed for temperature (both maximum and minimum). The 2009 crop season showed the lowest average wind speed $\left(2.0 \mathrm{~m} \mathrm{~s}^{-1}\right)$ of the data series. In terms of wind speed, the 2010 crop season $\left(2.4 \mathrm{~m} \mathrm{~s}^{-1}\right)$ was representative of an average season $\left(2.4 \mathrm{~m} \mathrm{~s}^{-1}\right)$.

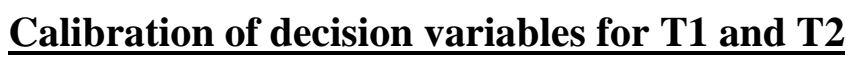

Table 1 presents the simulation results for the analyzed values of the decision variables for T1 (PAE IqMIN and $\left.S W D_{M A X}\right)$. Simulation results included the seasonal gross irrigation depth (mm), the seasonal average Uniformity Coefficient (\%), the seasonal average Application Efficiency (\%), and yield (\% of maximum). Average, maximum and minimum values of these variables are presented for each simulated variable, corresponding to the seasons included in the data series.

Increasing $P A E_{\text {IqMIN }}$ represents becoming more selective at the time of irrigation, requiring low wind speed and low sprinkler evaporation losses. This will generally concentrate irrigation during the night time and during non windy day time periods. On the contrary, $P A E_{l q M I N}=0 \%$ eliminates selection by $P A E_{l q}$ : irrigation will be accepted at any meteorological conditions, thus resulting in more inefficient water use. Decreasing the threshold for $S W D_{M A X}$ represents irrigating before plant stress develops. As a consequence, more irrigation events will be performed and more irrigation water will be used.

The selected values of the decision variables should promote water conservation without compromising crop yield. For the analyzed values of $S W D_{M A X}$, an important 
improvement in simulation results was observed from a value of $10 \mathrm{~mm}$ to a value of 20 $\mathrm{mm}$ (Table 1). The reduction in average irrigation depth was $87.5 \mathrm{~mm}$, while the average reduction in yield was $0.6 \%$. Simulation results for values of $S W D_{M A X}$ exceeding $20 \mathrm{~mm}$ were not adequate. Differences in $S W D_{M A X}$ between 20 and $25 \mathrm{~mm}$ resulted in a reduction in irrigation depth by about $2 \%(13.5 \mathrm{~mm})$, with a reduction in yield of $1.6 \%$. Thus, a value of $20 \mathrm{~mm}$ was selected for $S W D_{M A X}$.

Regarding $P A E_{\text {lqMIN }}$, improvements in irrigation performance were particularly relevant when increasing from 0 to $40 \%$. The reduction in the average irrigation depth was $10 \mathrm{~mm}$, but the increment in $C U$ was $2 \%$. Average yield remained basically constant. Increasing $P A E_{\text {lqMIN }}$ beyond $50 \%$ resulted in irrelevant decreases in irrigation depth. As a consequence, a value of $50 \%$ was selected for $P A E_{\text {lqMIN. }}$. In the analyzed time series the selected values provided an average grain yield of $96 \%$ of maximum, and an average application efficiency of $79 \%$. A value of $\Delta_{I E-A E}=10 \%$ was also determined from the simulation results.

Table 2 summarizes the simulation results of the calibration process for the decision variables controlling treatment $\mathrm{T} 2$. Increasing $E S_{\text {MAX }}$ resulted in slight decreases on irrigation depth, a slight improvement in irrigation performance and an unclear effect on crop yield. Accounting for the $P A E_{\text {IqMIN }}$ values, increasing the requirement for irrigation performance decreased the irrigation dose, increased the irrigation performance and slightly reduced yield. Considering the yield level established for T1, PAE $E_{\text {lqMIN }}$ was also limited to values lower or equal to $50 \%$. For this value of $P A E_{\text {lqMIN }}$, the yield level was only satisfied for $E S_{M A X}=0.5$ days. As a consequence, parameter values of $E S_{M A X}=0.5$ days and $P A E_{l q M I N}=50 \%$ were selected for $\mathrm{T} 2$ in the local conditions.

The meteorological data series, the soil properties and the network irrigation design of the experimental plots determine the selected values of the decision variables. It will be 
of interest to perform calibration processes for different meteorological conditions and diverse network configurations when analyzing different irrigation networks or locations. The calibration process could be improved by selecting different parameters for the different development crop stages and by basing the selection criteria of the decision variables on economical productivity more than on irrigation performance and crop yield. Corn water requirements greatly vary along the season. As a consequence, the effect of water stress on crop yield depends on corn phenology, permitting to adapt the thresholds of the control variables to particular conditions. Figure 4 presents the relationship between $P A E_{\text {lqMIN }}$ and Available Time for Irrigation (ATI, \%) for two representative months of the corn season. At the beginning of the corn season, April, satisfying crop water requirements only required about 33\% of the available time. As a consequence, a higher value of $P A E_{l q}$ can be used than for the peak of the season with the same ATI (Figure 4). In the middle of the corn season, July, the high crop water requirement occupied on average $70 \%$ of the $A T I$, the requirements on irrigation performance at this time need to be lowered. In order to accomplish the proposed improvement on the calibration process, the calibration procedure presented on Tables 1 and 2 could be independently implemented for each corn development phase.

\section{Experimental results}

The average $S W C_{I}$ in the 2009 crop season was $22.8 \%, 22.8 \%$ and $21.1 \%$ for treatments T0, T1 and T2, respectively. $S W C_{I}$ in the 2010 crop season was $25.2 \%, 24.2 \%$ and 23.6\% for treatments $\mathrm{T} 0, \mathrm{~T} 1$ and $\mathrm{T} 2$, respectively. Analysis of variance for $S W C_{I}$ indicated that the treatment factor was not statistically significant at the $95 \%$ confidence level (for both seasons). Statistical differences could not be established between treatments for $S W C_{F}$ (average of 22\%), FC (36\%), WP (22\%), or WHC (139 $\left.\mathrm{mm} \mathrm{m}^{-1}\right)$. 
Differences between treatments for plant height or IPAR were not statistically significant (Table 3), so plant growth was not affected by the irrigation treatments.

Table 4 presents simulated crop evapotranspiration and measured precipitation during the crop cycle for 2009 and 2010. The average and coefficient of variation of wind speed and relative humidity during the irrigation events are presented for each treatment. Finally, the seasonal irrigation depth, the seasonal coefficient of uniformity and the simulated irrigation efficiency are presented. Meteorological conditions in the 2009 irrigation season were far from average, particularly for wind speed and for the maximum temperatures. The 2010 irrigation season resulted in wind speeds similar to an average season. Consequently, the average wind speed during irrigation in 2009 was lower than in 2010. Wind variability in T0 was larger than in T1 and T2. $P A E_{l q}$ selection of irrigation timing in $\mathrm{T} 1$ and $\mathrm{T} 2$ reduced average wind speed respect to $\mathrm{T} 0$. As a consequence, in both irrigation seasons the irrigation depth was larger in T0 than in $\mathrm{T} 1$ or $\mathrm{T} 2$. On the average, the manual treatment applied $10 \%$ more water than $\mathrm{T} 1$ and 18\% more water than T2. Differences between treatments on simulated seasonal $C U$ resulted very low because of the compensatory effect on the $C U$ of the different irrigation events along the season (Dechmi et al., 2003). Differences between treatments in simulated seasonal irrigation efficiency were very important: the automatic treatments showed higher irrigation performance than the manual treatment. Average differences respect to T0 amounted to 6 and 7 percent points for T1 and T2, respectively. A large part of these differences was due to reductions in wind drift and evaporation losses.

Yield parameters are presented in Table 5. Grain yield was not affected by the irrigation treatment in any of the experimental years (Table 5). In 2009 there were not differences between irrigation treatments for aboveground biomass and harvest index. However, in 
2010 the aboveground biomass was significantly reduced in the T2 treatment. Since grain yield sampling size was $324 \mathrm{~m}^{2}$ and aboveground biomass and harvest index sampling size was only $4.5 \mathrm{~m}^{2}$, this reduction of aboveground biomass in the $\mathrm{T} 2$ treatment should be considered with caution. Water productivity (determined as the ratio between grain yield and irrigation depth) was statistically different for T0, T1 and T2 in the 2009 season. In the 2010 season, water productivity in T2 was higher than in $\mathrm{T} 0$ and $\mathrm{T} 1$. The values of water productivity grew from $\mathrm{T} 0$ to $\mathrm{T} 2 \mathrm{both}$ years.

The results of the field experiment indicate that the automatic controller prototype has accomplished its objective. The system has proved its potential to drastically reduce farmer dedication to irrigation. Compared with the manual treatment, the automated treatments increased irrigation efficiency, decreased irrigation depth and did not affect grain yield, which resulted in relevant increases in water productivity. In addition to these advantages related to indicators, the prototype punctually informed about incidences using the alarm protocols. Farmer intervention was only requested when needed to solve unexpected situations, mainly resulting from the irrigation hardware. 


\section{CONCLUSIONS}

A complex software-hardware automatic irrigation controller has been presented and applied to the analysis of a manual irrigation treatment and two automatic programming treatments differing in sophistication and on-farm computing requirements. The irrigation controller underwent a calibration of the parameters related to irrigation decision making. This process resulted in adequate parameter values: the performance indexes of the automatic treatments were larger than those of the manual treatment (for the irrigation results) or equal to those of the manual treatment (for the crop yield results). The calibration process can be improved in the future by using different values of the control parameters for the different corn crop stages.

The automatic controller prototype has minimized farmer intervention on irrigation practices, reducing human errors and increasing labor and water productivity. In fact, the prototype has been able to automatically schedule and execute seasonal irrigation obtaining high irrigation performance indexes, adjusted irrigation depths and competitive grain yields. The manual treatment applied an average of $10 \%$ more water than $\mathrm{T} 1$, and an average of $18 \%$ more than $\mathrm{T} 2$, without statistical differences in grain yield. T2 water productivity was the largest in both seasons.

Further research will need to focus on the inter-year performance variability of the automatic controller, as well as on the effect of climate on its performance in comparison with manual irrigation scheduling. Finally, the interaction between the automatic controller and irrigation hardware seems to be a key issue. It is of particular relevance to analyze the benefits derived from investing on time slack (for instance, through the number of on-farm irrigation blocks). 


\section{ACKNOWLEDGEMENTS}

The authors sequence in this paper follows the "first-last-author-emphasis" norm. This research was funded by the MCINN of the Government of Spain through grants AGL2007-66716-C03-01/02 and AGL2010-21681-C03-01. 


\section{REFERENCES}

Allen, R.G., Pereira, L.S., Raes, D. and Smith, M., 1998. Crop evapotranspiration: guidelines for computing crop water requirements. FAO irrigation and drainage paper 56, Rome, Italy, 300 pp.

Bruckler, L., Lafolie, F., Ruy, S., Granier, J., Baudequin, D. 2000. Modeling the agricultural and environmental consequences of non-uniform irrigation on a corn crop. 1. Water balance and yield. Agronomie. 20, 609-624.

Burt, C.M., Clemmens, A.J., Strelkoff, T.S., Solomon, K.H., Bliesner, R.D., A., H.L., Howell, T.A. and Eisenhauer, D.E., 1997. Irrigation performance measures: efficiency and uniformity. J. Irrig. Drain. Div., ASCE, 123(6), 423-442.

Camp, C. R. and Sadler E. J. 1998. Site specific crop management with a center pivot. Journal of Soil and Water Conservation 53(4): 312-314.

Cardenas-Lailhacar, B. and Dukes M.D. 2010. Precision of soil moisture sensor irrigation controllers under field conditions. Agricultural Water Management 97(5): 666-672.

Cavero, J., Medina E. T., Puig, M. and Martinez-Cob, A. 2009. Sprinkler Irrigation Changes Maize Canopy Microclimate and Crop Water Status, Transpiration, and Temperature. Agronomy Journal 101(4): 854-864.

Dechmi, F., Playán, E., Cavero, J., Faci, J.M, Martinez-Cob, A. 2003. Wind effects on solid-set sprinkler irrigation depth and yield of maize (Zea mays). Irrigation Science 22(2): 67-77.

Dechmi, F., Playán, E., Cavero, J., Martinez-Cob, A., Faci, J.M. 2004a. Coupled crop and solid-set sprinkler simulation model. I: Model development. Journal of Irrigation and Drainage Engineering-ASCE 130(6): 499-510.

Dechmi, F., Playán, E., Cavero, J., Martinez-Cob, A., Faci, J.M. 2004b. Coupled crop and solid-set sprinkler simulation model. II: Model application. Journal of Irrigation and Drainage Engineering-ASCE 130(6): 511-519.

Evans, R.G., Han S., Kroeger, M.W. 1995. Spatial-Distribution and Uniformity Evaluations for Chemigation with Center Pivots. Transactions of the Asae 38(1): 8592.

Evans, R. G., Buchleiter G. W., Sadler, E. J., King, B. A., Harting, G. B. 2000. Controls for precision irrigation with self-propelled systems. National Irrigation Symposium, Proceedings. St Joseph, AMER SOC AGR ENGINEERS: 322-331. 
Fukui, Y., Nakanishi, K. and Okamura, S., 1980. Computer evaluation of sprinkler irrigation uniformity. Irrig. Sci., 2: 23-32.

Goldhamer, D. A., Fereres E., Mata, M., Girona, J., Cohen, M. 1999. Sensitivity of continuous and discrete plant and soil water status monitoring in peach trees subjected to deficit irrigation. Journal of the American Society for Horticultural Science 124(4): 437-444.

Haley, M. B., Dukes M. D. and Miller, G. L. 2007. Residential irrigation water use in Central Florida. Journal of Irrigation and Drainage Engineering-Asce 133(5): 427434.

Intrigliolo, D. S. and J. R. Castel 2005. Effects of regulated deficit irrigation on growth and yield of young Japanese plum trees. J Hortic. Sci. Biotech. 80(2): 177-182.

Jones, H. G. 1990. Plant Water Relations and Implications for Irrigation Scheduling. International Symposium on Scheduling of Irrigation for Vegetable Crops under Field Condition, Vols 1 and 2. 278: 67-76.

King, B. A. and D. C. Kincaid (2004). "A variable flow rate sprinkler for site-specific irrigation management." Applied Engineering in Agriculture 20(6): 765-770.

Martinez-Cob, A. 2008. Use of thermal units to estimate corn crop coefficients under semiarid climatic conditions. Irrigation Science 26(4): 335-345.

McCready, M. S. and M. D. Dukes. 2011. Landscape irrigation scheduling efficiency and adequacy by various control technologies. Agricultural Water Management 98(4): 697-704.

Merriam, J.L. and Keller, J., 1978. Farm irrigation system evaluation: a guide for management. Utah State University, Logan, Utah, 271 pp.

Nadler, A. and M. T. Tyree 2008. Substituting stem's water content by electrical conductivity for monitoring water status changes. Soil Sci. Soc. Amer. J. 72(4): 10061013.

Naor, A., Y. Gal, Peres, M. 2006. The inherent variability of water stress indicators in apple, nectarine and pear orchards, and the validity of a leaf-selection procedure for water potential measurements. Irrig. Sci. 24(2): 129-135.

Playán, E., N. Zapata, Faci, J. M., Tolosa, D., Lacueva, J. L., Pelegrin, J., Salvador, R., Sanchez, I., Lafita, A. (2006). "Assessing sprinkler irrigation uniformity using a ballistic simulation model." Agricultural Water Management 84(1-2): 89-100. 
Roth, R.L. y B.R. Gardner. 1989. Asparagus yield response to water and nitrogen. Trans. ASAE 32: 105-112.

Smith, M., 1992. CropWat: a computer program for irrigation planning and management. FAO Irrig. and Drain. paper 46, Rome, Italy.

Stern, J., Bresler, E. 1983. Nonuniform sprinkler irrigation and crop yield. Irrig. Sci. 4, 17-29.

Zapata, N., Playán, E., Martínez-Cob, A., Sánchez, I., Faci, J. M. and Lecina, S. 2007. From on-farm solid-set sprinkler irrigation design to collective irrigation network design in windy areas. Agric. Wat. Manage., 87(2): 187-199.

Zapata, N., Playán, E., Skhiri, A. and Burguete, J. 2009. A collective solid-set sprinkler irrigation controller for optimum water productivity. J. Irrig. Drain. Eng., ASCE, 135 (1): 13-24.

Zapata, N., Nerilli, E., Martínez-Cob, A., Chalghaf, I., Chalghaf, B., Fliman, D. and Playán, E. 201X. Limitations to adopting regulated deficit irrigation in stone fruit orchards: A study case. Submitted to SJAR 


\section{LIST OF FIGURES}

Figure 1. Flow chart of the Ador-Control software. The left side of the figure presents the required input data. The irrigation performance module provides intermediate data that will be analyzed by the decision making module to produce automatic irrigation schedules.

Figure 2. Aerial photograph of the field experiment, detailing the location the software application, the hardware and the radio antenna. The experimental design (three treatments, four replicates) is presented. The location of the measurement points within each experimental plot is also presented

Figure 3. Graphical results of Ador-Control for Julian days 206 and part of 207, 2010. The processes involved in irrigation start, stop and resume for the three treatments (each of them equipped with six irrigation blocks) are presented. Black bars indicate that irrigation is in course. Grey areas indicate that irrigation is not allowed due to unsuitable meteorological conditions. Hourly values of selected meteors and irrigation performance indexes are presented at the right side of the Figure.

Figure 4. Relationship between $P A E_{\text {lqMIN }}$ and the available time for irrigation (ATI, \%), for two months of the cropping season (April and July) and for the local meteorological conditions. In the legend, in brackets, the monthly average required irrigation time (\%) is presented (deriving from local crop water requirements and irrigation system configuration). 


\section{LIST OF TABLES}

Table 1. Calibration of the decision variables controlling treatment $\mathrm{T} 1: S W D_{M A X}$ and $P A E_{\text {lqMIN. }}$ Simulated values of seasonal irrigation depth, seasonal $C U$, average $A E$ and simulated corn yield (percent of maximum) are presented for each combination of decision variables. Average (Avg), maximum (Max) and minimum (Min) values are presented for the calibration years.

Table 2. Calibration of the decision variables controlling treatment T2: $E S_{M A X}$ (days) and $P A E_{l q M I N}(\%)$. Simulated values of seasonal irrigation depth, seasonal $C U$, average $A E$ and simulated corn yield (percent of maximum) are presented for each combination of decision variables. Average (Avg), maximum (Max) and minimum (Min) values are presented for the calibration years.

Table 3. Plant height and intercepted photosynthetically active radiation (IPAR) for each irrigation treatment in the 2009 experiment.

Table 4. Simulated crop evapotranspiration $(E T c)$, measured seasonal precipitation $(P)$, measured average and coefficient of variation (between brackets) of wind speed and relative humidity, measured irrigation depth applied, and simulated seasonal $C U$ and $I E$ for each irrigation treatment during the two experimental years.

Table 5. Corn grain yield, aboveground biomass, harvest index and water productivity, in the different the irrigation treatments in the 2009 and 2010 experiments. 
Table 1. Calibration of the decision variables controlling treatment T1: $S W D_{M A X}$ and

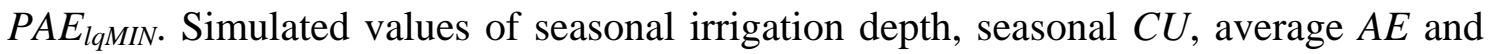
simulated corn yield (percent of maximum) are presented for each combination of decision variables. Average (Avg), maximum (Max) and minimum (Min) values are presented for the calibration years.

\begin{tabular}{|c|c|c|c|c|c|c|c|c|c|c|}
\hline \multirow{3}{*}{$\begin{array}{c}P A E_{\text {IqMIN }} \\
(\%)\end{array}$} & \multirow{3}{*}{ Variables } & \multicolumn{9}{|c|}{$S W D_{\text {MAX }}(\mathrm{mm})$} \\
\hline & & \multicolumn{3}{|c|}{10} & \multicolumn{3}{|c|}{20} & \multicolumn{3}{|c|}{25} \\
\hline & & Avg & Max & Min & Avg & Max & Min & Avg & Max & Min \\
\hline \multirow{4}{*}{0} & Irrigation depth $(\mathrm{mm})$ & 871 & 995 & 656 & 780 & 889 & 529 & 760 & 868 & 529 \\
\hline & CU (\%) & 86 & 90 & 81 & 85 & 89 & 80 & 85 & 89 & 79 \\
\hline & $A E(\%)$ & 69 & 72 & 65 & 76 & 81 & 71 & 77 & 82 & 70 \\
\hline & Yield (\%) & 98 & 99 & 95 & 97 & 98 & 96 & 96 & 98 & 94 \\
\hline \multirow{4}{*}{40} & Irrigation depth $(\mathrm{mm})$ & 858 & 952 & 656 & 768 & 868 & 529 & 752 & 868 & 529 \\
\hline & CU (\%) & 88 & 89 & 85 & 87 & 89 & 84 & 87 & 89 & 83 \\
\hline & $\mathrm{AE}(\%)$ & 71 & 73 & 68 & 77 & 82 & 71 & 78 & 83 & 70 \\
\hline & Yield (\%) & 98 & 100 & 93 & 97 & 98 & 94 & 96 & 99 & 92 \\
\hline \multirow{4}{*}{45} & Irrigation depth $(\mathrm{mm})$ & 843 & 931 & 656 & 752 & 825 & 550 & 742 & 825 & 529 \\
\hline & CU (\%) & 88 & 90 & 85 & 88 & 90 & 85 & 88 & 90 & 84 \\
\hline & $A E(\%)$ & 72 & 73 & 70 & 78 & 82 & 76 & 79 & 83 & 74 \\
\hline & Yield (\%) & 97 & 100 & 91 & 96 & 98 & 90 & 95 & 99 & 90 \\
\hline \multirow{4}{*}{50} & Irrigation depth $(\mathrm{mm})$ & 834 & 931 & 635 & 749 & 846 & 529 & 734 & 804 & 529 \\
\hline & CU (\%) & 89 & 91 & 87 & 89 & 90 & 86 & 89 & 90 & 86 \\
\hline & $A E(\%)$ & 72 & 74 & 68 & 79 & 83 & 73 & 79 & 84 & 75 \\
\hline & Yield (\%) & 96 & 100 & 86 & 96 & 98 & 84 & 94 & 98 & 83 \\
\hline \multirow{4}{*}{55} & Irrigation depth $(\mathrm{mm})$ & 820 & 889 & 635 & 740 & 805 & 550 & 720 & 804 & 508 \\
\hline & CU (\%) & 90 & 91 & 88 & 89 & 91 & 87 & 89 & 91 & 87 \\
\hline & $\mathrm{AE}(\%)$ & 73 & 75 & 67 & 79 & 83 & 74 & 80 & 86 & 74 \\
\hline & Yield (\%) & 95 & 100 & 78 & 95 & 99 & 81 & 93 & 98 & 75 \\
\hline
\end{tabular}


Table 2. Calibration of the decision variables controlling treatment T2: $E S_{M A X}$ (days) and $P A E_{\text {lqMIN }}(\%)$. Simulated values of seasonal irrigation depth, seasonal $C U$, average $A E$ and simulated corn yield (percent of maximum) are presented for each combination of decision variables. Average (Avg), maximum (Max) and minimum (Min) values are presented for the calibration years.

\begin{tabular}{|c|c|c|c|c|c|c|c|c|c|c|}
\hline \multirow{3}{*}{$\begin{array}{c}P A E_{\text {lqMIN }} \\
\text { (\%) }\end{array}$} & \multirow{3}{*}{ Variables } & \multicolumn{9}{|c|}{$E S_{M A X}$ (days) } \\
\hline & & \multicolumn{3}{|c|}{0.25} & \multicolumn{3}{|c|}{0.50} & \multicolumn{3}{|c|}{0.75} \\
\hline & & Avg & Max & Min & Avg & Max & Min & Avg & Max & Min \\
\hline \multirow{4}{*}{0} & $\begin{array}{l}\text { Irrigation depth } \\
(\mathrm{mm})\end{array}$ & 770 & 868 & 571 & 770 & 868 & 571 & 770 & 868 & 571 \\
\hline & CU (\%) & 85 & 87 & 80 & 85 & 87 & 80 & 85 & 87 & 80 \\
\hline & $\mathrm{AE}(\%)$ & 76 & 81 & 71 & 76 & 81 & 71 & 76 & 81 & 71 \\
\hline & Yield (\%) & 97 & 98 & 96 & 97 & 98 & 96 & 97 & 98 & 96 \\
\hline \multirow{4}{*}{40} & & 728 & 783 & 529 & 721 & 804 & 529 & 713 & 783 & 529 \\
\hline & CU (\%) & 86 & 89 & 83 & 87 & 89 & 82 & 87 & 89 & 82 \\
\hline & & 79 & 83 & 75 & 80 & 84 & 75 & 80 & 84 & 77 \\
\hline & Yield (\%) & 97 & 98 & 94 & 97 & 98 & 94 & 96 & 98 & 94 \\
\hline \multirow{4}{*}{45} & $\begin{array}{l}\text { Irrigation } \\
(\mathrm{mm})\end{array}$ & 719 & 825 & 508 & 705 & 805 & 508 & 698 & 762 & 507 \\
\hline & CU (\%) & 87 & 90 & 83 & 88 & 90 & 83 & 88 & 90 & 84 \\
\hline & & 80 & 83 & 76 & 81 & 84 & 77 & 81 & 84 & 78 \\
\hline & Yield (\%) & 96 & 98 & 94 & 95 & 98 & 92 & 95 & 98 & 92 \\
\hline \multirow{4}{*}{50} & $\begin{array}{l}\text { Irrigation depth } \\
(\mathrm{mm})\end{array}$ & 680 & 740 & 487 & 691 & 783 & 529 & 682 & 761 & 529 \\
\hline & CU (\%) & 87 & 89 & 82 & 88 & 90 & 84 & 88 & 90 & 85 \\
\hline & AE (\%) & 82 & 87 & 76 & 82 & 84 & 77 & 83 & 84 & 80 \\
\hline & Yield (\%) & 94 & 96 & 89 & 95 & 98 & 91 & 94 & 98 & 89 \\
\hline \multirow{4}{*}{55} & $\begin{array}{l}\text { Irrigation depth } \\
(\mathrm{mm})\end{array}$ & 677 & 741 & 487 & 682 & 741 & 529 & 671 & 741 & 529 \\
\hline & CU (\%) & 87 & 89 & 83 & 89 & 91 & 85 & 89 & 91 & 86 \\
\hline & $\mathrm{AE}(\%)$ & 82 & 86 & 78 & 82 & 84 & 79 & 83 & 85 & 81 \\
\hline & Yield (\%) & 93 & 96 & 90 & 94 & 98 & 88 & 93 & 98 & 88 \\
\hline
\end{tabular}


Table 3. Plant height and intercepted photosynthetically active radiation (IPAR) for each irrigation treatment in the 2009 experiment.

\begin{tabular}{|ccccc|}
\hline \multirow{2}{*}{ Treatment } & \multicolumn{2}{c}{ Plant height (m) } & \multicolumn{2}{c}{ IPAR (\%) } \\
\cline { 2 - 5 } & 24 June & 27 July & 23 July & 26 August \\
\hline T0 & $0.68 \mathrm{a}$ & $2.10 \mathrm{a}$ & $92.5 \mathrm{a}$ & $90.7 \mathrm{a}$ \\
T1 & $0.69 \mathrm{a}$ & $2.16 \mathrm{a}$ & $92.4 \mathrm{a}$ & $91.0 \mathrm{a}$ \\
T2 & $0.72 \mathrm{a}$ & $2.16 \mathrm{a}$ & $90.3 \mathrm{a}$ & $85.4 \mathrm{a}$ \\
\hline
\end{tabular}

For each variable and date the values followed by different letters are different, according to a Fisher Protected LSD test at $\mathrm{P}<0.05$. 
Table 4. Simulated crop evapotranspiration $(E T c)$, measured seasonal precipitation $(P)$, measured average and coefficient of variation (between brackets) of wind speed and relative humidity, measured irrigation depth applied, and simulated seasonal $C U$ and $I E$ for each irrigation treatment during the two experimental years.

\begin{tabular}{|c|c|c|c|c|c|c|c|c|}
\hline Season & Treatment & $\begin{array}{c}E T c \\
(\mathbf{m m})\end{array}$ & $\begin{array}{c}P \\
(\mathbf{m m})\end{array}$ & $\begin{array}{c}W S \\
\left(\mathrm{~m} \mathrm{~s}^{-1}\right)\end{array}$ & $\begin{array}{l}\text { RH } \\
\text { (\%) }\end{array}$ & $\begin{array}{c}\text { Irrigation } \\
\text { depth } \\
\text { (mm) }\end{array}$ & $\begin{array}{c}\text { Seasonal } \\
C U(\%)\end{array}$ & $\begin{array}{c}I E \\
(\%)\end{array}$ \\
\hline \multirow{3}{*}{2009} & T0 & \multirow{3}{*}{695} & \multirow{3}{*}{69} & $1.1(64)$ & $60(37)$ & 862.3 & 89.9 & 76.3 \\
\hline & T1 & & & $0.9(56)$ & $62(31)$ & 740.6 & 89.3 & 81.3 \\
\hline & $\mathbf{T} 2$ & & & $1.0(40)$ & $61(30)$ & 703.6 & 88.6 & 84.7 \\
\hline \multirow{3}{*}{2010} & T0 & \multirow{3}{*}{698} & \multirow{3}{*}{134} & $1.4(86)$ & $68(32)$ & 714.2 & 90.5 & 81.4 \\
\hline & T1 & & & $1.2(58)$ & $67(30)$ & 693.0 & 91.0 & 86.8 \\
\hline & T2 & & & $1.3(62)$ & $67(30)$ & 629.5 & 90.6 & 86.3 \\
\hline
\end{tabular}


Table 5. Corn grain yield, aboveground biomass, harvest index and water productivity, in the different the irrigation treatments in the 2009 and 2010 experiments.

\begin{tabular}{|c|c|c|c|}
\hline \multirow{2}{*}{ Varaible } & \multirow{2}{*}{ Treatment } & 2009 & 2010 \\
\hline & & Average & Average \\
\hline \multirow{3}{*}{$\begin{array}{l}\text { Grain Yield } \\
\left.\text { (kg ha }^{-1}\right)\end{array}$} & T0 & $16,262 \mathrm{a}$ & $16,192 \mathrm{a}$ \\
\hline & $\mathrm{T} 1$ & $15,412 \mathrm{a}$ & $15,820 \mathrm{a}$ \\
\hline & T2 & $15,645 \mathrm{a}$ & $15,455 \mathrm{a}$ \\
\hline \multirow{3}{*}{$\begin{array}{l}\text { Aboveground } \\
\text { Biomass } \\
\left(\mathrm{kg} \mathrm{ha}^{-1}\right)\end{array}$} & T0 & $28,478 \mathrm{a}$ & $27,512 \mathrm{a}$ \\
\hline & $\mathrm{T} 1$ & $25,941 \mathrm{a}$ & $26,841 \mathrm{a}$ \\
\hline & $\mathrm{T} 2$ & 26,440 a & $23,457 \mathrm{~b}$ \\
\hline \multirow{3}{*}{$\begin{array}{c}\text { Harvest } \\
\text { Index } \\
(-)\end{array}$} & T0 & $0.57 \mathrm{a}$ & $0.58 \mathrm{a}$ \\
\hline & $\mathrm{T} 1$ & $0.59 \mathrm{a}$ & $0.58 \mathrm{a}$ \\
\hline & $\mathrm{T} 2$ & $0.59 \mathrm{a}$ & $0.65 \mathrm{~b}$ \\
\hline \multirow{3}{*}{$\begin{array}{c}\text { Water } \\
\text { Productivity } \\
\left(\mathrm{kg} \mathrm{m}^{-3}\right)\end{array}$} & T0 & $1.88 \mathrm{a}$ & $2.23 a$ \\
\hline & $\mathrm{T} 1$ & $2.08 \mathrm{~b}$ & $2.25 \mathrm{a}$ \\
\hline & $\mathrm{T} 2$ & $2.22 \mathrm{c}$ & $2.42 \mathrm{~b}$ \\
\hline
\end{tabular}

For each variable and year the values followed by different letters are different according to a Fisher Protected LSD test at $\mathrm{P}<0.05$. 
Figure 1. Flow chart of the Ador-Control software. The left side of the figure presents the required input data. The irrigation performance module provides intermediate data that will be analyzed by the decision making module to produce automatic irrigation schedules.

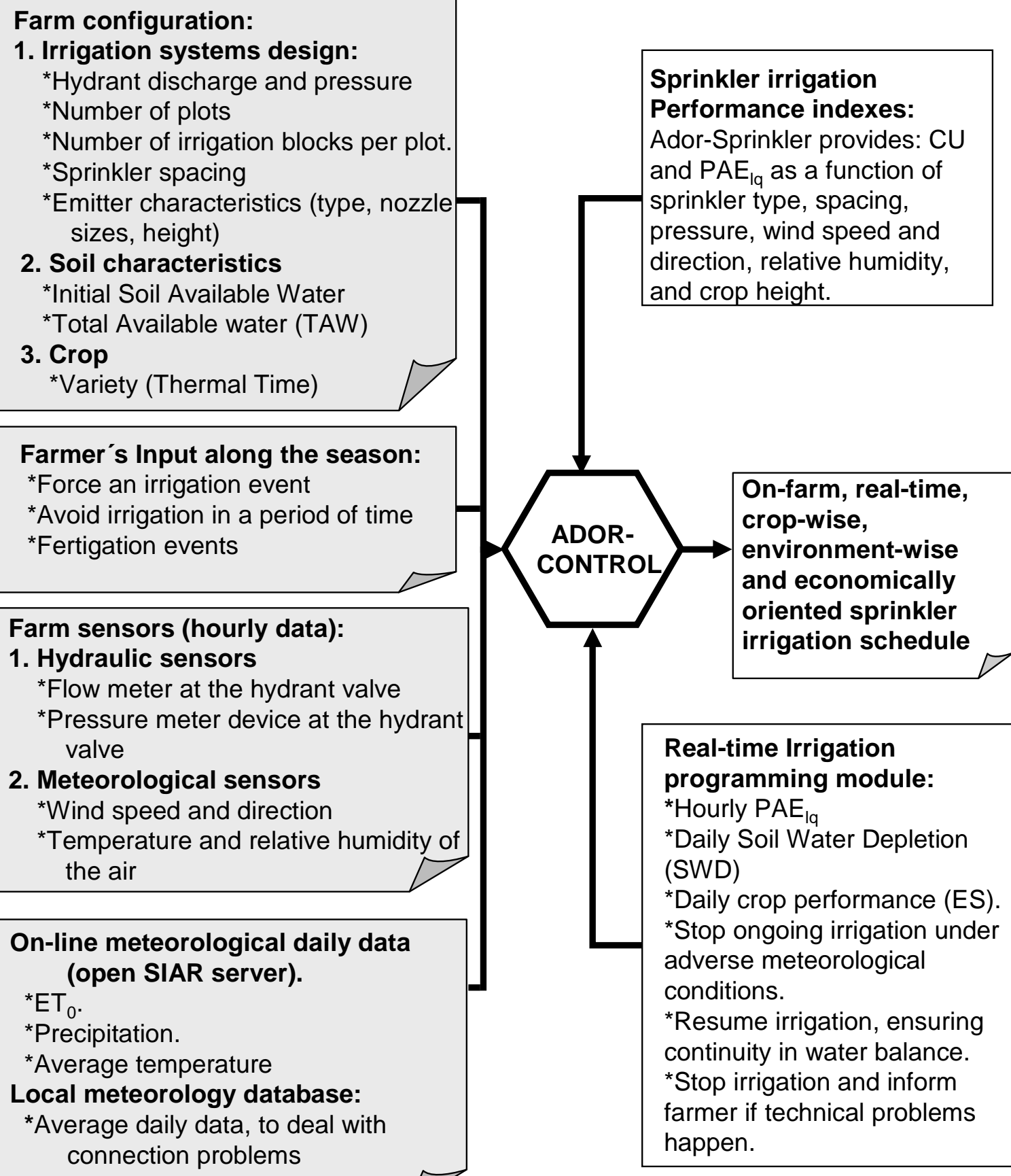

On-line meteorological daily data (open SIAR server).$$
{ }^{\star} \mathrm{ET}_{0} \text {. }
$$

*Precipitation.

*Average temperature

Local meteorology database:

*Average daily data, to deal with connection problems

Sprinkler irrigation Performance indexes: Ador-Sprinkler provides: $\mathrm{CU}$ and $P A E_{I q}$ as a function of sprinkler type, spacing, pressure, wind speed and direction, relative humidity, and crop height.

Real-time Irrigation
programming module:
${ }^{*}$ Hourly PAE $\mathrm{I}_{\mathrm{lq}}$
${ }^{*}$ Daily Soil Water Depletion
(SWD)
${ }^{*}$ Daily crop performance (ES).
*Stop ongoing irrigation under
adverse meteorological
conditions.
*Resume irrigation, ensuring
continuity in water balance.
*Stop irrigation and inform
farmer if technical problems
happen.


Figure 2. Aerial photograph of the field experiment, detailing the location the software application, the hardware and the radio antenna. The experimental design (three treatments, four replicates) is presented. The location of the measurement points within each experimental plot is also presented.

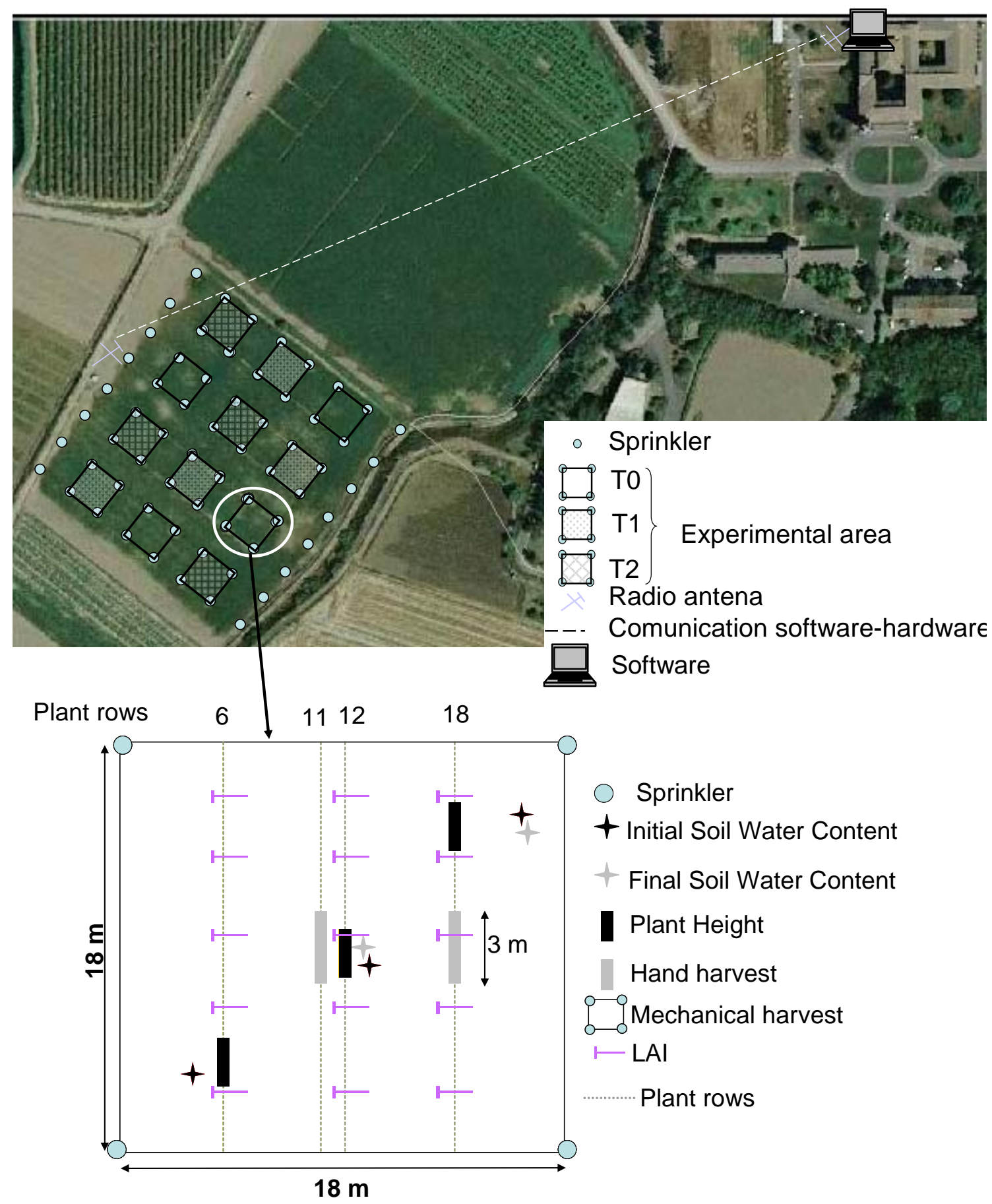


Figure 3. Graphical results of Ador-Control for Julian days 206 and part of 207, 2010. The processes involved in irrigation start, stop and resume for the three treatments (each of them equipped with six irrigation blocks) are presented. Black bars indicate that irrigation is in course. Grey areas indicate that irrigation is not allowed due to unsuitable meteorological conditions. Hourly values of slected meteors and irrigation performance indexes are presented at the right side of the Figure.

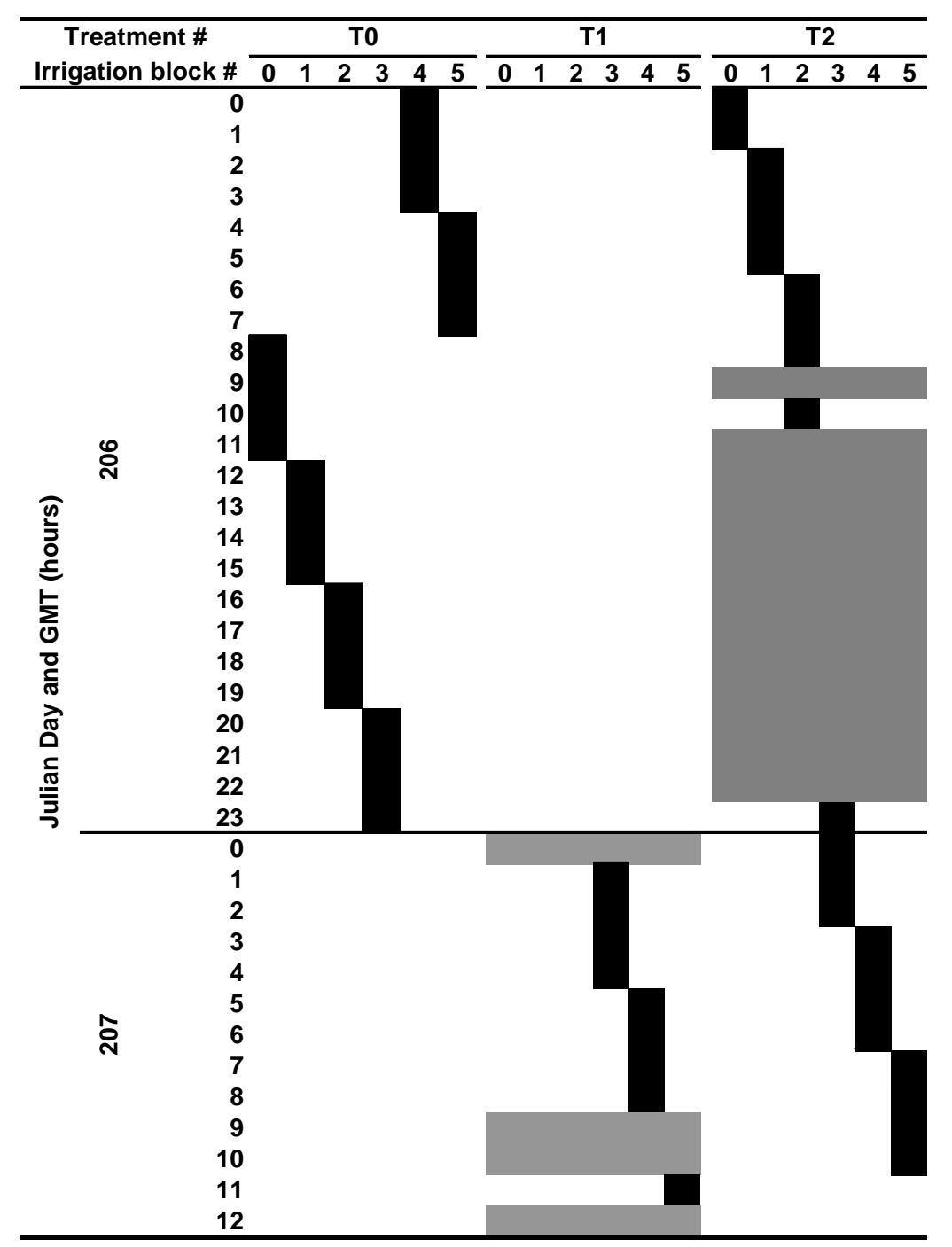

\begin{tabular}{ccccc}
\hline $\begin{array}{c}\mathrm{WS} \\
\left(\mathrm{m} \mathrm{s}^{-1}\right)\end{array}$ & $\begin{array}{c}\mathrm{RH} \\
(\%)\end{array}$ & $\begin{array}{c}\mathrm{T}^{\mathrm{a}} \\
\left({ }^{\circ} \mathrm{C}\right)\end{array}$ & $\begin{array}{c}\mathrm{CU} \\
(\%)\end{array}$ & $\begin{array}{c}\mathrm{PAE}_{\mathrm{lq}} \\
(\%)\end{array}$ \\
\hline 2.6 & 70 & 18 & 89 & 70 \\
3.2 & 70 & 17 & 81 & 60 \\
3.6 & 78 & 17 & 75 & 55 \\
1.2 & 80 & 17 & 91 & 83 \\
2.6 & 82 & 17 & 86 & 67 \\
2.1 & 82 & 18 & 88 & 73 \\
1.9 & 82 & 19 & 88 & 73 \\
1.5 & 83 & 21 & 90 & 79 \\
1.1 & 79 & 22 & 92 & 83 \\
4.9 & 73 & 24 & 63 & 39 \\
3.0 & 67 & 26 & 81 & 59 \\
4.5 & 61 & 27 & 68 & 43 \\
5.8 & 57 & 27 & 59 & 33 \\
4.4 & 57 & 28 & 69 & 44 \\
4.4 & 51 & 27 & 68 & 42 \\
4.6 & 48 & 27 & 69 & 42 \\
5.7 & 45 & 25 & 60 & 35 \\
4.8 & 46 & 24 & 65 & 38 \\
4.8 & 49 & 22 & 66 & 40 \\
5.8 & 53 & 21 & 57 & 35 \\
6.3 & 60 & 21 & 52 & 31 \\
4.9 & 65 & 20 & 62 & 38 \\
4.2 & 71 & 20 & 71 & 48 \\
3.6 & 76 & 19 & 76 & 53 \\
4.8 & 78 & 19 & 62 & 39 \\
2.7 & 79 & 19 & 86 & 67 \\
2.9 & 80 & 19 & 80 & 61 \\
3.6 & 78 & 18 & 75 & 54 \\
2.2 & 79 & 18 & 88 & 73 \\
2.1 & 78 & 19 & 88 & 73 \\
2.1 & 79 & 20 & 88 & 73 \\
2.2 & 83 & 21 & 88 & 74 \\
2.8 & 83 & 23 & 80 & 62 \\
4.0 & 74 & 25 & 71 & 50 \\
4.4 & 67 & 26 & 68 & 44 \\
3.4 & 64 & 27 & 76 & 52 \\
4.2 & 58 & 28 & 72 & 47 \\
\hline & & & &
\end{tabular}


Figure 4. Relationship between $P A E_{\text {lqMIN }}$ and the available time for irrigation (ATI, \%), for two months of the cropping season (April and July) and for the local meteorological conditions. In the legend, in brackets, the monthly average required irrigation time (\%) is presented (deriving from local crop water requirements and irrigation system configuration).

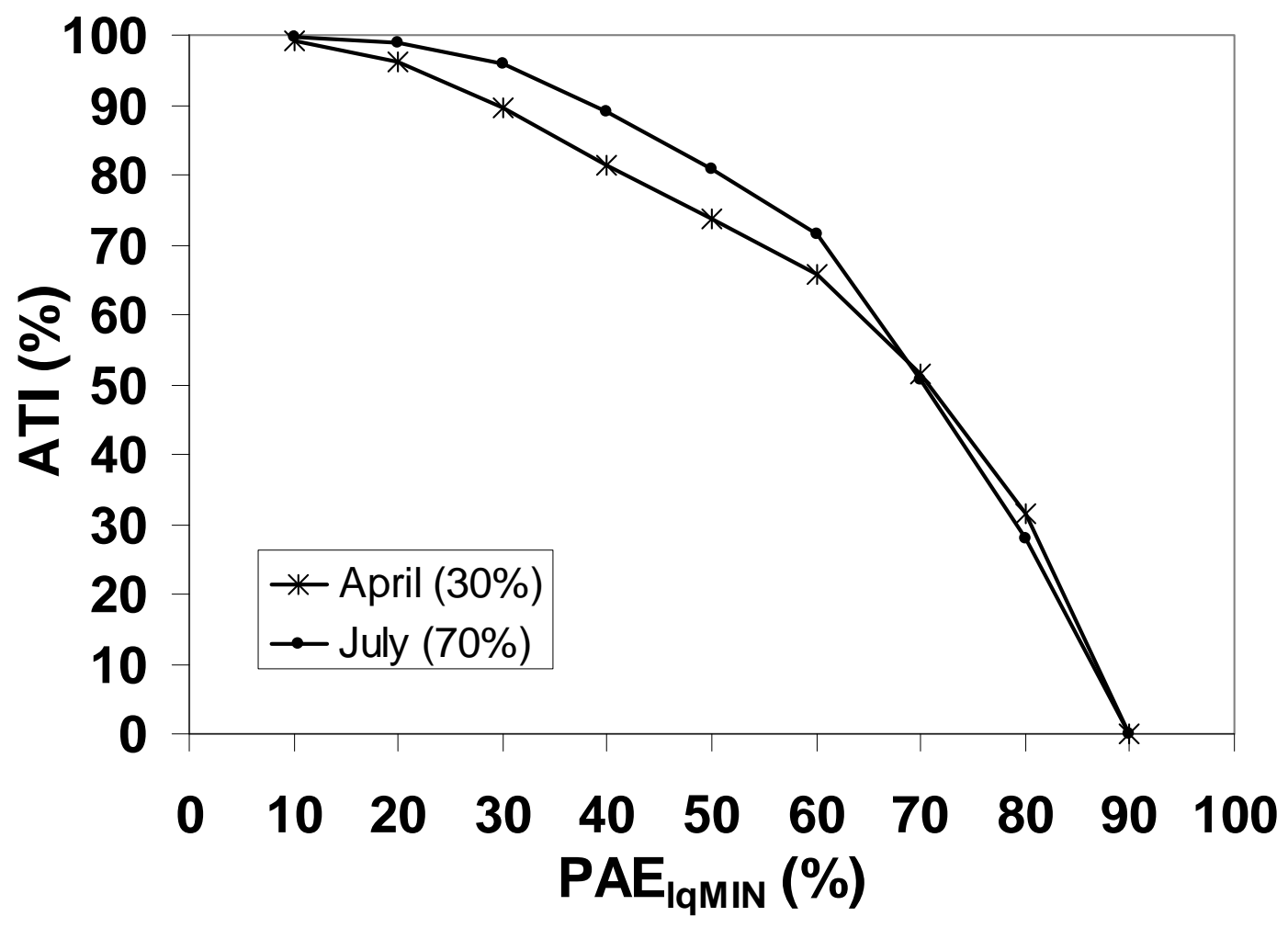

